\title{
Phenotypic variation in the Snowtrout Schizothorax richardsonii (Gray, 1832) (Actinopterygii: Cypriniformes: Cyprinidae) from the Indian Himalayas
}

\author{
Farooq A. Mir ${ }^{1}$, Javaid I. Mir ${ }^{2,4}$, Suresh Chandra ${ }^{3}$ \\ ${ }^{1}$ Postgraduate Department of Zoology, University of Kashmir, Hazratbal, 190006, Srinagar, Jammu \& Kashmir, India \\ ${ }^{2}$ Directorate of Coldwater Fisheries Research, Indian Council of Agricultural Research, Anusandhan Bhawan \\ Bhimtal-263136, Nainital, Uttarakhand, India \\ ${ }^{3}$ National Bureau of Fish Genetic Resources, Canal Ring Road, Dilkusha, Lucknow, 226002, Uttar Pradesh India \\ ${ }^{4}$ E-mail:r.javaid@rediffmail.com
}

Key words: discriminant function analysis, India, shape, trans-Himalaya, truss box

\begin{abstract}
We investigated intraspecific variation of the Snowtrout, Schizothorax richardsonii on the basis of morphometric characters. Altogether, 217 specimens were collected from four rivers in the Western and Central Indian Himalaya. A truss network was constructed by interconnecting 14 landmarks to yield 31 distance variables that were extracted from digital images of specimens using tpsDig2 and PAST software. Transformed truss measurements were subjected to univariate analysis of variance, factor analysis and discriminant analysis. All variables exhibited significant differences between the populations. Altogether $86.6 \%$ of the specimens were classified into their original populations ( $82.9 \%$ under a 'leave-one-out' procedure). With factor analysis measurements of the head region, the middle portion and the caudal region had high loadings on the on first and second axis. The results indicated that $S$. richardsonii has significant phenotypic heterogeneity between the Western and Central Indian Himalayas. We hypothesize that the marked interspecific variation in S. richardsonii is the result of local ecological conditions.
\end{abstract}

\section{Contents}

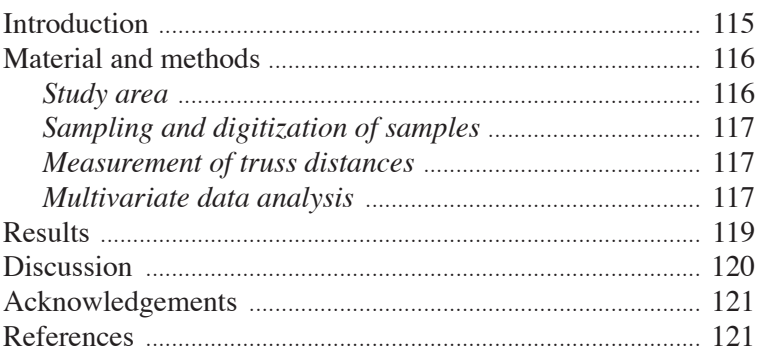

\section{Introduction}

The study of morphological characters, with the aim of defining or characterizing fish stock units, has for some time been a strong interest in ichthyology (Cadrin, 2000). In general, a 'fish stock' is a local population adapted to a particular environment, having genetic differences from other stocks (MacLean and Evans, 1981). Although genetic differences between stocks are a condition of this definition, phenotypic variations still continue to have an important role in stock identification among groups of fish (Costa et al., 2003). The usage of phenotypic characters is particularly important where the differences are attributed to environmental influences rather than to genetic differentiation (Mir et al., 2013a).

Various tools, such as meristics and morphometrics, traditional tags, parasites as natural tags, otolith chemistry, molecular genetics and electronic tags have been used for the purpose of stock identification, among which the study of morphometric traits is one of the frequently employed and cost-effective methods. Traditional multivariate morphometrics, accounting for variation in size and shape, have successfully discriminated between many fish stocks (Turan, 1999). However, traditional methods have been enhanced by image processing techniques, through better data collection, more effective descriptions of shape, and new analytical tools. The development of image analysis systems has facilitated progress and diversification of morphometric methods and expands the potential for using morphometry as a tool for stock identification (Cadrin and Friedland, 1999; Mir et al., 2013b). Truss network is much more powerful in identifying intraspecific groups with different life history stages according to shape variation than manual measurements (Strauss and Bookstein, 1982; Bookstein, 1991). The methodology is predicated on the measurement of across-body distances connecting two morphological landmarks 
from a sequential series of connected polygons. This type of landmark-based technique using geometric morphometrics imposes no restrictions on the direction of variation and localization of shape changes and is highly effective in capturing information about the shape of an organism (Cavalcanti et al., 1999).

The fishes of genus Schizothorax are the members of the family Cyprinidae, commonly known as snowtrouts, consist of 15 genera and over 100 species all over the world (Mirza, 1991). In India, these species are distributed in the cold waters from Jammu and Kashmir (Sunder and Bhagat, 1979), to Assam and Eastern Himalayas through Bhutan and Sikkim at an elevation of 1180-3000 $\mathrm{m}$ (Jhingran, 1982). So, far 28 species of snow trout have been reported in the Himalayan and Sub-Himalayan regions. Their inherent biological features, such as short growth period and slow growth to maturity, are the main constraints hindering their growth and population increase (Mir et al., 2012). This species of this genus are remarkably similar in general morphology and are often difficult to distinguish based on external morphological characters across the Indian Himalayas (Chandra et al., 2012). The taxonomy of these fishes has been studied from time to time (Negi and Negi, 2010; Mir et al., 2012) but a clear picture of their status has not been available till recently in a consolidated form (Vishwanath, 2010; Chandra et al., 2012).

Schizothorax richardsonii (Gray, 1832) is a coldwater fish, commonly known as Snowtrout, classified as vulnerable (VU) in India by the IUCN (2012). The distribution of this cyprinid species is confined to the Himalayan and Sub-Himalayan rivers and streams along Jammu and Kashmir, Himachal Pradesh, Uttarakhand, Assam and Sikkim. Besides India, this species is distributed in Bhutan, Nepal, Pakistan and Afghanistan (Talwar and Jhingran, 1991). Although S. richardsonii is widely distributed along the Himalayan foothills and previous studies have indicated that it is abundantly and commonly found, but recent observations indicate drastic decline in the populations of many areas of its range due to introduction of exotic species, damming and overfishing (Negi and Negi, 2010). There is a strong belief that if alien species introductions are carried out throughout its range, this species may be completely displaced by exotic salmonids (Vishwanath et al.,2010). The phenomenon of slow growth, poor disease resistance and low survival rate are serious threats, which greatly affect the enhancement and stocking program. Therefore, the present study was considered as a first step towards the aim of exploring the stock structure of this species based on morphometric characters, using truss network system for its successful development and management across the Indian Himalaya.

\section{Material and methods}

\section{Study area}

The Himalaya is the youngest mountain chain on the planet and is believed to be still evolving, and thereby, is both geologically and geomorphologically unstable. Because of its extremely active geodynamic condition, even small tampering with the geoecological balance can initiate environmental changes that may eventually lead to alarming proportion (Bilham and Gaur, 2000; Valdiya, 2003). The Indian Himalayan region (IHR) stretches over $2500 \mathrm{~km}$ from Jammu and Kashmir in the West to Arunachal Pradesh in the East, between $21^{\circ} 57^{\prime}-37^{\circ} 5^{\prime} \mathrm{N}$ latitudes and $72^{\circ} 40^{\prime}-97^{\circ} 25^{\prime} \mathrm{E}$ longitudes. This great chain of mountains in Indian territory extends all along the northern border of the country from the eastern border of Pakistan in the West to the frontiers of Myanmar in the east covering partially/ fully twelve states of India, viz., Jammu and Kashmir, Himachal Pradesh, Uttarakhand, Sikkim, Arunachal Pradesh, Nagaland, Manipur, Mizoram, Tripura, Meghalaya and hills of Assam and West Bengal.

The Indian Himalayas are mainly drained by 19 rivers, including three major river systems; the Indus, Ganga and Brahmaputra. The Indus Basin system is the longest river system which originates from Western Indian Himalaya $\left(160,000 \mathrm{~km}^{2}\right)$ and consist of five rivers. The Ganga basin system contributes nine rivers and originates from Central Indian Himalaya $\left(150,000 \mathrm{~km}^{2}\right)$ and the Brahmaputra basin is the second longest river system which starts in Eastern Himalaya $\left(150,000 \mathrm{~km}^{2}\right)$ having five rivers (Hora, 1954). This study includes four rivers two from Western Himalaya (Jhelum and Lidder) and two from Eastern Himalaya (Alaknanda and Mandakini). River Jhelum is a tributary of Indus basin and has a total length of about $813 \mathrm{~km}$; it originates from Verinag Spring situated at the southeastern part of the valley of Kashmir in India. The Lidder River is the second largest tributary of river Jhelum covering $73 \mathrm{~km}$ distance in the Kashmir region of India and its source (Kolhoi Glacier) is located at a height of 4,653 masl (meters above sea level). These are the two least explored rivers of Western Himalaya and are an important fishery resource for the daily living of the local people. River Alaknanda is a tributary of the river Ganga basin of Central Himalaya in Uttarakhand. It is about $190 \mathrm{~km}$ 
long and originates from Satopanth Glacier in Garhwal Himalaya (Menon, 1954). River Mandakini is the least explored tributary of river Alaknanda. These two rivers are full of fish and play a critical role in the regional economy and food security of the people.

\section{Sampling and digitization of samples}

A total of 217 Schizothorax richardsonii specimens were collected from four different rivers across Indian Himalaya viz. Jhelum, Lidder, Alaknanda and Mandakini, by using different fishing gear (cast nets and gill nets) from January 2011 to November 2011 and analyzed for morphometric variations. The specimens of $S$. richardsonii were obtained before the breeding season and after the spawning period to avoid a bias toward size difference. The mesh size of the fishing gear (cast nets: $9 \mathrm{~m}$ length, $9 \mathrm{~m}$ breadth and $1 / 2 \mathrm{~cm}$ mesh size and drag nets: $100 \mathrm{~m}$ length, $20 \mathrm{~m}$ breadth, $1 / 2 \mathrm{~cm}$ mesh size) was designed for the large sized specimens to any avoid fingerling and fry capture. The GPS coordinates, altitude (masl), flow rate $\left(\mathrm{ms}^{-1}\right.$; meter per second), number of samples, min-max length and weight of $S$. richardsonii across the Indian Himalaya are presented in Table 1.

The sampled specimens were first cleaned in running water, drained and placed on a flat platform with graph paper as a background for calibrating the coordinates of digital images. The fins were erected to make the origin and insertion points visible. Each individual was labelled with a specific code to identify it. A Sony Cybershot DSC-W300 digital camera was used for capturing the digital images. To avoid errors in image capture all photos were taken by a single person from same angle and height at every shot. After image capture, each fish was dissected to identify the sex by macroscopic examination of the gonads. Gender was used as the class variable in ANOVA to test for significant dif- ferences in the morphometric characters, if any, between males and females of $S$. richardsonii.

\section{Measurement of truss distances}

The extraction of truss distances from the digital images of specimens was conducted using a linear combination of three software platforms, tpsUtil, tpsDig2 v2.1 (Rohlf, 2006) and Paleontological Statistics (PAST; Hammer et al., 2001). The truss protocol used for the S. richardsonii was based on fourteen landmarks (Fig. $1 \mathrm{AB})$. A box truss of 31 lines connecting these landmarks was generated for each fish to represent the basic shape of the fish (Strauss and Bookstein, 1982; Mir et al., 2013b). All the measurements were transferred to a spreadsheet file (Excel 2007), and the X-Y coordinate data transformed into linear distances by computer (using the Pythagorean Theorem) for subsequent analysis.

\section{Multivariate data analysis}

Size dependent variation was corrected by adopting an allometric method as suggested by Elliott et al.(1995):

$\mathrm{M}_{\text {adj }}=\mathrm{M}\left(\mathrm{L}_{\mathrm{s}} / \mathrm{L}_{0}\right)^{\mathrm{b}}$

where $\mathrm{M}$ is original measurement, $\mathrm{M}_{\mathrm{adj}}$ is the size adjusted measurement, $\mathrm{L}_{0}$ is the standard length of the fish, $\mathrm{L}_{\mathrm{s}}$ the overall mean standard length, and $b$ was estimated for each character from the observed data as the slope of the regression of $\log M$ on $\log \mathrm{L}_{0}$ using all fish from every group. The results derived from the allometric method were confirmed by testing significance of the correlation between transformed variables and standard length (Turan, 1999). Univariate analysis of variance (ANOVA) was performed for the 31 morphometric characters to evaluate the significant difference

Table 1. GPS coordinates, altitude (masl; meters above sea level), flow rate $\left(\mathrm{ms}^{-1}\right.$; meters per second), number of samples, min-max. length and weight of Schizothorax richardsonii across the Indian Himalaya.

\begin{tabular}{|c|c|c|c|c|}
\hline \multirow[t]{2}{*}{ Parameters } & \multicolumn{4}{|l|}{ rivers (sites) } \\
\hline & Alaknanda (Pauri) & Mandakini (Kedarnath) & Jhelum (Srinagar) & Lidder (Pahalgam) \\
\hline latitude ${ }^{\circ} \mathrm{N}$ & $30^{\circ} 10^{\prime} 31^{\prime \prime}$ & $30^{\circ} 43^{\prime} 59^{\prime \prime}$ & $34^{\circ} 8^{\prime} 20^{\prime \prime}$ & $34^{\circ} 0^{\prime} 45^{\prime \prime}$ \\
\hline longitude ${ }^{\circ} \mathrm{E}$ & $78^{\circ} 37^{\prime} 24^{\prime \prime}$ & $79^{\circ} 4^{\prime} 6^{\prime \prime}$ & $74^{\circ} 40^{\prime} 52^{\prime \prime}$ & $75^{\circ} 18^{\prime} 56^{\prime \prime}$ \\
\hline altitude (masl) & 1814 & 3588 & 1584 & 2740 \\
\hline maximum flow rate $\left(\mathrm{ms}^{-1}\right)$ & 1.43 & 1.53 & 1.38 & 1.92 \\
\hline number of samples & 69 & 41 & 58 & 49 \\
\hline $\min -\max \mathrm{tl}(\mathrm{cm})$ & $10.5-48.6$ & $12.3-51.5$ & $9.8-45.3$ & $10.2-40.5$ \\
\hline $\min -\max$ bw $(\mathrm{g})$ & $35.5-700$ & $28.3-800.4$ & $30.4-680.4$ & $32.6-610.9$ \\
\hline
\end{tabular}



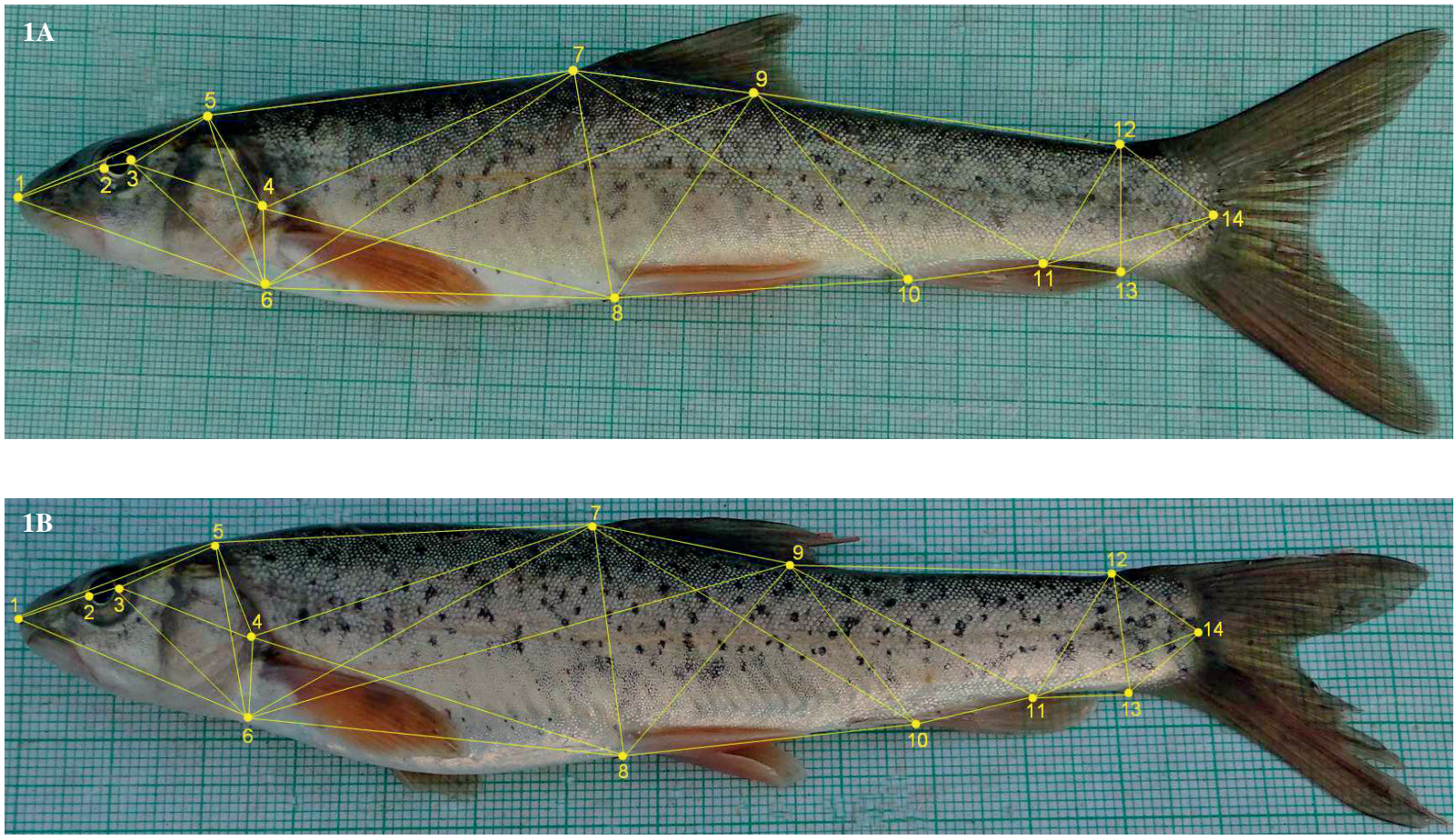

Fig. 1. Schematic image of S. richardsonii depicting the 14 landmarks and associated box truss used to infer morphological differences among populations. 1 Tip of snout; 2 end of eye towards mouth; 3 end of eye towards tail; 4 end of operculum; 5 forehead (end of frontal bone); 6 dorsal origin of pectoral fin; 7 origin of dorsal fin; 8 origin of pelvic fin; 9 termination of dorsal fin; 10 origin of anal fin; 11 termination of anal fin; 12 dorsal side of caudal peduncle, at the nadir; 13 ventral side of caudal peduncle, at the nadir; 14 end of lateral line (Adapted from truss box, after Strauss and Bookstein (1982) and Bookstein (1991)). Fig 1A (Western Himalaya), Fig 1B (Central Himalaya).

between the four locations. These 31 transformed truss measurements were subjected to FACTOR analysis, to explain these variables in terms of their common underlying dimensions. A maximum likelihood method was used to extract the factors. With the assistance of Scree plot, the cumulative variance explained by the factors and the meaningful biological groupings of the traits loading on each factor were taken into consideration to retain the number of factors for a rotation procedure. The retained factors were subjected to a Varimax rotation procedure and to identify the variables demonstrating high loadings for a given factor, the rotated factors were subjected to a scratching procedure, as described by Hatcher (2003). The Wilks' $\lambda$ was used to compare the difference between all groups. The discriminant function analysis (DFA) was used to calculate the percentage of correctly classified (PCC) fish and a cross-validation using PCC was done to estimate the expected actual error rates of the classification functions. Statistical analyses for morphometric data were performed using the SPSS vers. 16.1.0 and Microsoft Excel 2007.

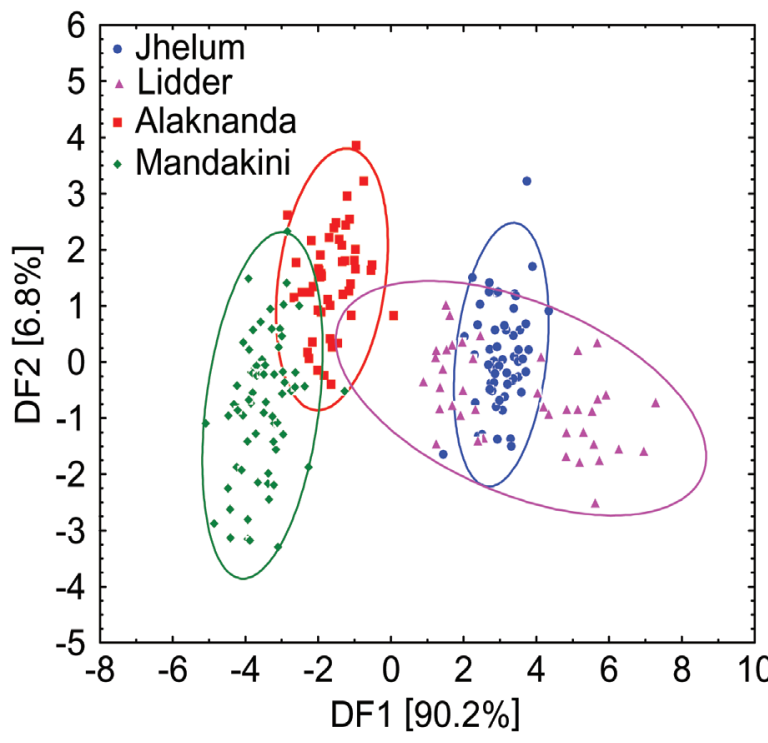

Fig. 2. Discriminant analysis plot for morphometric variables Schizothorax richardsonii collected from four rivers across from Indian Himalaya. 
Table 2. Results of Wilks' lambda tests of the discriminant function analysis (function 1 through 3 ) of morphometric variables of Schizothorax richardsonii collected from four rivers across Indian Himalaya.

\begin{tabular}{lllrl}
\hline Test of Function(s) & Wilks' Lambda & Chi-square & df & Sig. \\
\hline 1 through 3 & .062 & 581.554 & 27 & .000 \\
2 through 3 & .519 & 137.554 & 16 & .000 \\
3 & .806 & 45.168 & 7 & .000 \\
\hline
\end{tabular}

Table 4. Percentage of specimens classified in each group and after cross validation for morphometric measurements of Schizothorax richardsonii from four rivers across Indian Himalaya (86.6\% of original grouped cases correctly classified, $82.9 \%$ of cross-validated grouped cases correctly classified).

\begin{tabular}{lrrrrr}
\hline \multicolumn{7}{c}{ Original group (\%) } \\
\cline { 2 - 6 } Rivers & Jhelum & Lidder & Alaknanda & Mandakini & Total \\
\hline Jhelum & 81.0 & 19.0 & .0 & .0 & 100.0 \\
Lidder & 17.1 & 78.0 & 4.9 & .0 & 100.0 \\
Alaknanda & .0 & .0 & 91.8 & 8.2 & 100.0 \\
Mandakini & .0 & .0 & 7.2 & 92.8 & 100.0 \\
\hline & \multicolumn{7}{c}{$\begin{array}{l}\text { Cross-validated (\%) } \\
\text { Jhelum }\end{array}$} & 77.6 & 22.4 & .0 & & \\
Lidder & 19.5 & 73.2 & 7.3 & .0 & 100.0 \\
Alaknanda & .0 & .0 & 89.8 & 10.2 & 100.0 \\
Mandakini & .0 & .0 & 11.6 & 88.4 & 100.0 \\
\hline
\end{tabular}

\section{Results}

None of the size-adjusted truss measurements showed a significant correlation with the standard length of the fish, indicating that the variation in body length had been successfully removed by the allometric transformation. Among four selected rivers, means of all the truss measurements of $S$. richardsonii were found to be significantly $(\mathrm{P}<0.001)$ different in univariate analysis of variance. The morphometric characters between two sexes did not differ significantly $(\mathrm{P}>0.05)$ hence; the data for both sexes were pooled for all subsequent analysis.

A common problem with many fish morphology studies that use multivariate analysis is a potentially inadequate sample size. For decades, authors of theoretical works on DFA recommended that the ratio of the number of organisms measured $(\mathrm{N})$, relative to the parameters included $(\mathrm{P})$ in the analysis, should be at least 3-3.5 (Kocovsky et al., 2009). Small N values may fail to adequately capture covariance or morphological
Table 3. Contribution to discriminant functions (DFs) of morphometric variables of Schizothorax richardsonii collected from four rivers across Indian Himalaya. *indicates largest absolute correlation between each variable and any discriminant function.

\begin{tabular}{|c|c|c|c|}
\hline \multirow{2}{*}{$\begin{array}{l}\text { Function } \\
\text { Character }\end{array}$} & \multirow[b]{2}{*}{ DF1 [90.2\%] } & \multirow[b]{2}{*}{ DF2 [6.8\%] } & \multirow[b]{2}{*}{ DF3 [3.0\% } \\
\hline & & & \\
\hline $1-6$ & $.573(*)$ & -.069 & -.184 \\
\hline $10-11$ & $.510(*)$ & .091 & .063 \\
\hline $6-9$ & $.506(*)$ & .095 & .022 \\
\hline $11-14$ & $.483(*)$ & .129 & .466 \\
\hline $12-14$ & $.476(*)$ & -.322 & .027 \\
\hline $8-9$ & $.470(*)$ & .063 & .211 \\
\hline $3-6$ & $.444(*)$ & .177 & -.337 \\
\hline $13-14$ & $.396(*)$ & -.102 & -.065 \\
\hline $3-5$ & $.383(*)$ & -.329 & .127 \\
\hline $5-6$ & $.360(*)$ & .126 & -.325 \\
\hline $11-12$ & $.350(*)$ & .239 & .190 \\
\hline $6-7$ & $.252(*)$ & -.101 & -.186 \\
\hline $2-3$ & $.208(*)$ & -.128 & .147 \\
\hline $11-13$ & $.188(*)$ & .020 & .179 \\
\hline $9-10$ & -.044 & $.629(*)$ & .215 \\
\hline $9-11$ & .445 & $.552(*)$ & .176 \\
\hline $7-10$ & .165 & $.540(*)$ & -.072 \\
\hline $9-12$ & .391 & $.501(*)$ & .179 \\
\hline $1-5$ & .289 & $-.393(*)$ & .288 \\
\hline $4-6$ & .359 & $.365(*)$ & -.336 \\
\hline $1-2$ & .053 & $-.349(*)$ & .273 \\
\hline $7-9$ & .242 & $.278(*)$ & -.189 \\
\hline $3-4$ & .159 & -.162 & $.519(*)$ \\
\hline $4-8$ & .341 & .359 & $-.501(*)$ \\
\hline $4-7$ & .367 & -.046 & $-.454(*)$ \\
\hline $8-10$ & .384 & .222 & $.452(*)$ \\
\hline $5-7$ & .329 & -.067 & $-.396(*)$ \\
\hline $7-8$ & .180 & .118 & $-.310(*)$ \\
\hline $4-5$ & .241 & -.269 & $-.303(*)$ \\
\hline $6-8$ & .167 & .118 & $-.230(*)$ \\
\hline $12-13$ & .023 & .036 & $.162(*)$ \\
\hline
\end{tabular}

variation, which may lead to false conclusions regarding differences among groups (McGarigal et al., 2000). In the present investigation all 31 characters were retained and under these circumstance the N:P ratio was 7.0.

The Wilks $\lambda$ tests of discriminant analysis indicated significant differences in morphometric characters of four populations, and all the functions were highly significant $(\mathrm{P}<0.001$; Table 2$)$.

Plotting DF1 and DF2 showed clear between-sample differentiation (Fig. 2). The first DF accounted for $90.2 \%$ and the second accounted for $6.8 \%$ of the between group variability, explaining $97 \%$ of the total between groups variability. All the samples from the rivers of Western and Central Indian Himalayan regions 
were clearly separated from each other in discriminant space. However, Alaknanda River showed slight overlapping with Mandakini River and river Jhelum showed intermingling with Lidder River.

Pooled within-group correlations between discriminating variables and DFs revealed that fourteen body measurements (1-6, 10-11, 6-9, 11-14, 12-14, 8-9, 3-6, $13-14,3-5,5-6,11-12,6-7,2-3$ and 11-13) covering whole organism contributed dominantly to first DF. The loadings on second DF (9-10, 9-11, 7-10, 9-12, 1-5, 4-6, 1-2 and 7-9) dominantly contributed to head, middle region and caudal peduncle of the fish. The third DF loadings (3-4, 4-8, 4-7, 8-10, 5-7, 7-8, 4-5, 6-8 and 1213) were concentrated on opercular and predorsal region, implying that these characters are the most important in the description of population characteristics (Table 3). Factor loadings are correlations between the variables and the factors. In the present study the variables loaded on first, second and third factors were mostly positive indicating the positive correlation between the variables within a factor. This relationship is expected as the variables loading on first factor belonged to the middle portion of the body and these traits grow proportionately with one another. Another reason for positive loadings of variables may be, due to the rotation of the factors which helps to reduce the number of negative loadings to a minimum.

The classification of individuals into their original population varied between $78.0 \%$ and $92.8 \%$ by discriminant analysis and $86.6 \%$ of individuals could be classified into their original a priori grouping (Table 4). The proportion of correctly classified Mandakini River samples into their original population was the highest $(92.8 \%)$. A cross-validation test using leave one out procedure was also performed by which $82.9 \%$ of the samples were correctly classified into their original populations. The slight intermingling was observed between rivers of Western Himalaya (Jhelum and Lidder; $19 \%$ misclassification) and between rivers of Central Himalaya (Alaknanda and Mandakini; 7.2\% misclassification; Table 4).

\section{Discussion}

In general, fishes show higher degree of variation within and between populations than other vertebrates, and are more susceptible to environmentally induced morphological variation (Wimberger, 1992). Such variation in morphology is commonly due to the isolation of portions of a population within local habitat conditions. A sufficient degree of isolation may result in notable phenotypic and genetic differentiation among fish populations within a species, as a basis for separation and management of distinct populations (Turan, 2004). Such differentiation can occur through different processes. For example, reproductive isolation between different stocks of fishes may arise by homing to different spawning areas (Hourston, 1982) or by hydrographic features, which reduce or prevent migration between areas (Iles and Sinclair, 1982). Failure to recognize or to account for stock complexity in management units has led to an erosion of spawning components, resulting into a loss of genetic diversity, and other unknown ecological consequences (Begg et al., 1999).

The results obtained from the truss-based morphometrics indicated that the $S$. richardsonii showed significant phenotypic heterogeneity between the two geographically isolated Himalayan regions. Discriminant function analysis (DFA) could be useful method to distinguish different stocks of the same species (Karakousis et al., 1991). In the present investigation, $86.6 \%$ of individuals were correctly classified into their respective groups by DFA, indicating high variation between two stocks. Turan et al. (2004) studied Anchovy, Engraulis encrasicolus (Linnaeus, 1758) from the parts of Mediterranean Sea, finding significant morphometric heterogeneity among different populations by applying DFA and attributed it to migration of the fish. The DFA confirmed that the variation in morphological measurements was evident in the head region, eye diameter, body depth and caudal peduncle, between these morphologically distinct populations of snowtrout. Hossain et al. (2010) applied DFA and PCA on three populations of Labeo calbasu (Hamilton, 1822) from river Jamuna, Halda and hatchery and reported morphological discrimination among them due to the environmental factors and local migration of the fish. Similar observations were noticed by Khan et al. (2012) in case of Channa punctatus (Bloch, 1793) from three Indian rivers and lead the conclusion that environmental conditions play an important role in spatial distribution, movement and isolation of fish stocks. Mir et al. (2013a,b) observed similar inferences in Schizopyge niger (Heckel, 1838)) and Labeo rohita (Hamilton, 1822) from Indus basin and Ganga basin respectively, and attributed to changing physical and ecological conditions of water bodies.

The width of sampling location on the Jhelum River is more than $100 \mathrm{~m}$ with extensive human development. A large scale of diversions is present on this river which 
almost de-waters the natural channel towards upstream. The Pahalgam sampling station on the Lidder River is less than $50 \mathrm{~m}$ wide with less human interruption and minimally-regulated towards the upstream. This may be one of the reasons of stock divergence between these two rivers. River Lidder is largely fragmented due to presence of water impoundments and is broken into a large number of small streams for the irrigation purpose, which has resulted into the fishery stock divergence and ultimately to intraspecific morphological dichotomy. The variation among the stocks of four populations of two geographically isolated parts of Himalaya could also be a consequence of phenotypic plasticity in response to uncommon hydrological conditions like differences in alkalinity, current pattern, temperatures, turbidity, and land-use pattern among these rivers. The closeness between the stocks may be due to their similar habitat attributes and environmental impacts.

The causes of morphological differences among different populations are often quite difficult to explain. It has been suggested that the morphological characters of fish are determined by genetic, environment and the interaction between them (Poulet et al., 2004). The environmental factors prevailing during the early development stages, when the individual's phenotype is more amenable to environmental influence is of particular importance (Pinheiro et al., 2005). The phenotypic variability may not necessarily reflect population differentiation at the molecular level (Ihssen et al., 1981). Apparently, the fragmentation of river impoundments can lead to an enhancement of pre-existing genetic differences, providing a high interpopulation structuring (Esguicero and Arcifa, 2010). Thus, the possibility exists that the observed morphological variations in the present study might be due to genetic differences among the populations.

The truss system can be successfully used to investigate stock separation within a species, as reported for other species in freshwater and marine environments. In this study, the truss protocol revealed a clear separation of S. richardsonii stocks observed from two distinct geographic regions of Indian Himalaya, suggesting a need for separate management strategy to sustain the stock for future use. The observation given in the present study can further be confirmed based on molecular and biochemical methods. Application of molecular genetic markers such as microsatellite and mtDNA applications along with morphometric studies would be effective methods to further examine the genetic component of phenotypic discreteness between geographic regions and to facilitate the development of management recommendations. This additional examination would provide further confirmation of the stock structure resolved in this study with the truss analysis. However, further management measures have to be taken by the enforcement of mesh size regulation and imposition of a closed season during the breeding of some commercially important fish species in Himalayan regions to sustain this resource for the future use.

\section{Acknowledgements}

The authors are grateful to the fishermen for their help in fish capture. The authors would also like to thank Dr. Costa and an anonymous reviewer for their constructive comments regarding this work.

\section{References}

Begg G, Friedland KD, Pearce JB. 1999. Stock identification - its role in stock assessment and fisheries management. Fisheries Research 43: 1-8.

Bilham R, Gaur VK. 2000. Geodetic contributions of the study of seismotectonics in India. Current Science 79: 12591269.

Bookstein FL. 1991. Morphometric tools for landmark data. Cambridge: Cambridge University Press.

Cadrin SX. 2000. Advances in morphometric identification of fishery stocks. Reviews in Fish Biology and Fisheries 10: 91-112.

Cadrin SX, Friedland KV. 1999. The utility of image processing techniques for morphometric analysis and stock identification. Fisheries Research 43: 129-139.

Cavalcanti MJ, Monteiro LR, Lopez PRD. 1999. Landmark based morphometric analysis in selected species of Serranid fishes (Perciformes: Teleostei). Zoological Studies 38: 287-294.

Chandra S, Matura R, Barat A, Singh BK. 2012. Development of novel microsatellite markers for threatened species, Schizothorax richardsonii from the Trans-Himalaya, India. Molecular Ecology Resources 12: 1196-1197.

Costa JL, Almeida PR, Costa MJ. 2003. A morphometric and meristic investigation of Lusitanian toadfish Halobatrachus didactylus (Bloch and Schneider, 1081): evidence of population fragmentation on Portuguese coast. Scientia Marina 67: 219-231.

Elliott NG, Haskard K, Koslow JA. 1995. Morphometric analysis of orange roughly (Hoplostethus atianticus) off the continental slope of Southern Australia. Journal of Fish Biology 46: 202-220.

Esguicero ALH, Arcifa SA. 2010. Fragmentation of a Neotropical migratory fish population by a century old dam. Hydrobiologia 638: 41-53.

Hammer O, Harper DAT, Ryan PD. 2001. PAST: paleontological statistics software package for education and data analysis. Palaeontologia Electronica 4: 9. 
Hatcher L. 2003. A step by step approach to using Sas for factor analysis and structural equational modeling. SAS Institute Inc., Cary. Nic, pp. 57-125.

Hora SL. 1954. The evolution of the Indian torrential environment and its fishes. Bulletin of National Institute of Sciences of India 17: 437-444.

Hossain MAR, Nahiduzzaman M, Habiba KDS, Mst U, Alam MS. 2010. Landmark-based morphometric and meristic variations of the endangered Carp, Kalibaus Labeo calbasu, from stocks of two isolated rivers, the Jamuna and Halda, and a hatchery. Zoological Studies 49: 556-563.

Hourston AS. 1982. Homing by Canada's west coast herring to management units and divisions as indicated by tag recoveries. Canadian Journal of Fisheries and Aquatic Sciences 39: 1414-1422.

Ihssen PE, Booke HE, Casselman JM, McGlade JM, Payne NR, Utter FM. 1981. Stock identification: materials and methods. Canadian Journal of Fisheries and Aquatic Sciences 38: 1838-1855.

Iles TD, Sinclair M. 1982. Atlantic herring stock discreteness and abundance. Science 215: 627-633.

IUCN. 2012 Red List of Threatened Species, vers. 2012.1. [accessed June 2012]

Jhingran VG. 1982. Fish and Fisheries of India. Hindustan Publishing Corporation.

Karakousis Y, Triantaphyllidis C, Economidis PS. 1991. Morphological variability among seven populations of brown trout, Salmon trutta L., in Greece. Journal of Fish Biology 38: 807817.

Khan MA, Miyan K, Khan S. 2012. Morphometric variation of snakehead fish, Channa punctatus, populations from three rivers. Journal of Applied Ichthyology 28: 154-155.

Kocovsky PM, Adams JV, Bronte CR. 2009. The effect of sample size on the stability of principal component analysis of trussbased fish morphometrics. Transactions of the American Fisheries Society 138: 487-496.

MacLean JA, Evans DO. 1981. The stock concept, discreteness of fish stocks, and fisheries management. Canadian Journal of Fisheries and Aquatic Sciences 38: 1889-1898.

McGarigal K, Cushman S, Stafford S. 2000. Multivariate Statistics for Wildlife and Ecology Research. New York: Springer Verlag.

Menon AGK. 1954. Fish geography of the Himalayas. Zoological Survey of India 15: 467-493.

Mir JI, Shabir R, Mir FA. 2012. Length-weight Relationship and Condition Factor of Schizopyge curvifrons (Heckel 1838) from River Jhelum, Kashmir, India. World Journal of Fisheries and Marine Sciences 4:325-329.

Mir JI, Mir FA, Chandra S, Patiyal RS, 2013a. Pattern of morphological variations in Alghad snowtrout, Schizopyge niger (Heckel 1838) from Kashmir Himalaya using truss network analysis. Ichthyological Research 60: 256-262.
Mir JI, Sarkar UK, Dwivedi AK, Gusain OP, Jena JK. 2013 b. Stock structure analysis of Labeo rohita (Hamilton, 1822) across the Ganga basin (India) using a truss network system. Journal of Applied Ichthyology doi: 10.1111/jai.12141.

Mirza MR. 1991. A contribution to the systematics of the Schizothoracine fishes (Pisces: Cyprinidae) with the description of three new tribes. Pakistan Journal of Zoology 23: 339-341.

Negi RK, Negi T. 2010. Analysis of morphometric characters of Schizothorax richardsonii (Gray 1832) from the Uttarkashi District of Uttarakhand State, India. Journal of Biological Sciences 10: 536-540.

Pinheiro A, Teixeira CM, Rego AL, Marques JF, Cabral HN. 2005. Genetic and morphological variation of Solea lascaris (Risso, 1810) along the Portuguese coast. Fisheries Research 73: 67-78.

Poulet N, Berrebi P, Crivelli AJ, Lek S, Argillier C. 2004. Genetic and morphometric variations in the pikeperch (Sander lucioperca L.) of a fragmented delta. Archiv für Hydrobiologie 159: 531-554.

Rohlf FJ. 2006.tpsDig2, vers. 2.1. State University of New York, Stony Brook. [available via http://life.bio.sunysb.edu/morph]

Strauss RE, Bookstein FL. 1982. The truss: body form reconstruction in morphometrics. Systematic Zoology 31: 113-135.

Sunder S, Bhagat MJ. 1979. A note on the food of Schizothorax plagiostomus (McClelland) in the Chenab drainage of Jammu Province during 1973-74. Journal of Inland Fisheries Society of India 11: 117-118.

Talwar PK, Jhingran GA. 1991. Inland fisheries of India and adjacent countries, vol. I and II. New Delhi: Oxford and IBH Publishing Company Pvt. Limited.

Turan C. 1999. A note on the examination of morphometric differentiation among fish populations: the truss system. Turkish Journal of Zoology 23: 259-263.

Turan C. 2004. Stock identification of Mediterranean horse mackerel (Trachurus mediterraneus) using morphometric and meristic characters. ICES Journal of Marine Sciences 61: 774-781.

Valdiya KS. 2003. Reactivation of Himalayan frontal fault: implication. Current Science 85: 1031-1040.

Vishwanath W. 2010. Schizothorax richardsonii. In: IUCN 2011. IUCN Red List of Threatened Species, vers. 2011 .2. [accessed 27 October 2010]

Wimberger PH. 1992. Plasticity of fish body shape. The effects of diet, development, family and age in two species of $G e$ ophagus (Pisces, Cichlidae). Biological Journal of Linnaean Society 45: 197-218.

Received: 25 January 2013

Revised and accepted: 7 June 2013

Published online: 13 September 2013

Editor: R. Vonk 